\title{
Land price polarization and dispersion in Tokyo: a spatial model approach
}

\author{
Yuta Kanno ${ }^{1} \cdot$ Takayuki Shiohama $^{2}$
}

Received: 26 April 2021 / Accepted: 16 November 2021 / Published online: 4 January 2022

(c) The Japan Section of the Regional Science Association International 2021

\begin{abstract}
Intensifying spatial inequality in housing markets is of great concern for urban planners and policymakers. This study employed a year-on-year analysis using universal kriging to fit the official land price data in Tokyo over the period 1997-2021. By comparing estimated regression coefficients with the estimated spatial variogram parameters, we found evidence of rising spatial polarization and dispersion in land prices of Tokyo. This was confirmed via price differences between western and central Tokyo that are becoming larger with each passing year. The determinants of the land price have different impacts on prices in western and central Tokyo. As for the variogram parameter, the nugget effects of the residuals in spatial models are increasing for the non-central region and decreasing in central Tokyo, which indicates that the degree of spatial dispersion is increasing.
\end{abstract}

Keywords Generalized least squares method · Land price dispersion · Spatial polarization $\cdot$ Spatial variogram $\cdot$ Tokyo land prices

JEL Classification C21 $\cdot \mathrm{R} 12 \cdot \mathrm{R} 32$

\section{Introduction}

Intensifying spatial inequality in housing markets is a big concern for urban planners and policymakers. Spatial housing market polarization is defined as increasing disparities between sub-regions with high values and those with low values.

Takayuki Shiohama

shiohama@nanzan-u.ac.jp

Yuta Kanno

4417702@ed.tus.ac.jp

1 Graduate School of Engineering, Tokyo University of Science, 6-3-1 Niijyuku, Katsushika, Tokyo 125-8585, Japan

2 Department of Data Science, Nanzan University, 18 Yamasato cho, Showa, Nagoya 466-8673, Japan 
Modai-Snir and van Ham (2018) studied increasing inequality between urban development area and rural fringe in Tel Aviv, Israel, and found that this inequality is associated with changing socio-spatial structure due to the integration of the global economy. Arundel and Hochstenbach (2020) found that driving inequalities in housing wealth accumulation is related to spatial polarization that divides housing access among the population in the Netherlands. Hochstenbach and Arundel (2020) studied spatial polarization across different scales at the national, provincial, and urban levels using house-value development analysis in the Netherlands over time and space. The process of how spatial inequality divides Tokyo was studied by Kubo (2020), where she stated that the suburban areas facing the aging of their residents and an increase in vacant housing increase spatial inequality between the growth in city centers and the shrinking suburbs. The literature on spatial polarization deals with the relationship between socio-economic conditions and housing markets that varies over time and space. There is little research on how this polarization is formed throughout the varying structure of the spatial and environmental conditions of the housing market.

Land price polarization is closely related to increasing land price dispersion. Price dispersion is defined by the variation in prices across the same products with the same characteristics. In a housing market, price dispersion occurs spatially and temporally. The degree of the housing price dispersion was measured by calculating the standard deviation and skewness of the prices (Leung et al. 2006). Van Nieuwerburgh and Weill (2010) explained the increase in the level of aggregate house price, and the increase in its dispersion across regions using the US house prices data by calibrating a dynamic general equilibrium model, and found that the rise in house price dispersion across regions in the US was related to the changes in income distribution across regions. Ohnishi et al. (2020) investigated the cross-sectional distribution of house prices in the Greater Tokyo Area for the period 1986-2009 and found that the spatial heterogeneity is increasing, leading to an increase in price inequality across properties. In this study, we evaluate the degree of land price dispersion by estimating spatial variogram parameters, where the spatial concentration can be interpreted in terms of spatial autocorrelation, and the spatial autocorrelation affects the spatial variograms.

Real estate is a factor of production in our economy, and its value reflects both the qualitative and quantitative aspects of economic activity. This study empirically examines how the land price polarization progresses in Tokyo. The temporal variation of land price and its determinants can provide an insight into how rising land price inequality is formed across temporal and spatial variations. To understand the dynamics of rising land price polarization, this study employs a year-on-year analysis using universal kriging to fit the official land price data in Tokyo over the last 25 years.

Statistical analyses of real estate prices are typically investigated using the hedonic approach. The hedonic approach is a technique for measuring non-market asset values, mainly by using regression models. Examples of explanatory variables in regression models include environmental quality and social capital. Through land and house models, it is possible to observe how differences in environmental conditions can result in differences in the prices of land and houses. Early studies of 
the hedonic approach, including the housing market analysis, are present in Rosen (1974) and Goodman (1978). For further details, refer to Hill (2013).

Constructing a land price model with accurate forecasting performances using the ordinary least squares (OLS) method requires collecting a large volume of land price data together with sufficiently large explanatory variables. Not all factors that have an impact on land prices are observable, and the error of land price models has spatial and time-series correlation because the real estate evaluation depends on the surrounding environment and time trend. In spatial statistics, there is a technique called "kriging," which originated from Matheron (1963). It assumes second-order stationarity in a random field of a spatial process and expresses the covariance of the observed data as a function of distance, structures the spatial correlation, and makes a spatial prediction of the value of the random field at an arbitrary point. Kriging is a statistical method that uses a structured covariance function to obtain a spatial predictor that is the best linear unbiased prediction. Universal kriging is a method of spatial prediction based on the regression residuals of a land price model ${ }^{1}$. In kriging, one needs to estimate a variogram function. A variogram is a key function in geostatistics and is used to display the variability between data points as a function of distance. Using a mathematical model that describes spatial patterns on variograms, several useful parameters were examined. Since the "range," "sill," and "nugget" values of the estimated variogram parameters indicate certain degrees of spatial correlation and dispersion, investigating the transition of these parameters can provide information on how spatial polarization and dispersion intensifies across regions and time ${ }^{2}$.

This study focuses on annual changes in the regression coefficients of spatial process models in the universal kriging of official land prices and spatial variogram parameters focusing on how spatial polarization progresses and land price dispersion increases. While many studies have described how useful kriging is, few have looked at the annual changes in spatial process model coefficients or spatial variograms. Inoue et al. (2007) compared the regression coefficients of the land price model of each use district using a spatio-temporal model and evaluated spatio-temporal variograms by comparing the goodness of fit and estimation accuracy. However, their study aimed to visualize the land price changes. Our approach is investigating how the parameters in variograms change as time progresses. Chica-Olmo et al. (2019) investigated a hedonic regression model to estimate housing prices and the spatial variability of prices over multiple years in the city of Granada, Spain. They used the regression-cokriging method to predict housing prices and obtained isovalue maps of these spatial variations.

\footnotetext{
1 See, for example, Derdouri and Murayama (2020), where they studied the spatial prediction of the land price in Fukushima prefecture based on geostatistical methods.

2 The nugget represents an estimate of the semi-variance or co-variance between observations collected at "zero lag distance apart." The sill is an estimate of the total variance explained by the spatial structure analysis. The range is an estimate of the maximum distance at which point observations are spatially correlated.
} 
Our main findings are as follows. First, the changes in parameters that represent convenience in a way widen the price differences between the eastern and western regions of Tokyo. Such factors include the distance from the closest station, the access index, and the land area. Spatial polarization can be attributed to the different effects of such factors, included in the hedonic land price functions explained in Sect. 3. In addition, the preference for brands has caused the official land prices in the southeast region to soar, a tendency that grows stronger every year. Second, the land price dispersion increases as the nugget and sill parameters of the variogram increase. The increase in spatial dispersion can also be explained by the increase in importance of the individual factors. Such individual factors may include hazard map caution areas, crime, local noises, and sunshine conditions, which are not included in this study. These results suggest the possibility of stabilizing land price polarization by controlling the factors of land price functions.

This paper is structured as follows: In Sect. 2, we explain the urban structure of Tokyo, which is the subject of our research. In addition, the data used to estimate the land price models are explained in Sect. 2. We also provide information about the spatial inequality of land price distribution and the degree of spatial land price dispersion by plotting the average rate of changes in prices throughout the analysis period. In Sect. 3, the variograms in the spatial process models and universal kriging are explained. Investigating the transition of estimated model parameters provides information on the sources of the land price polarization and dispersion. In Sect. 4, the estimated land price models and spatial variograms are presented. In Sect. 5, summaries and discussions of this study are presented, and several future research topics are explained.

\section{Urban structure of Tokyo and data}

\subsection{Urban structure of Tokyo}

The urban structure of Tokyo has been studied in many fields from different perspectives. Since urban form significantly impacts urban sprawl and transportation, changes in the urban structure of Tokyo have garnered attention not only in the field of urban planning, but also in demography, transportation, environment, and economics. See, for examples, Hatta and Ohkawara (1993), Sakai et al. (2016), Zheng (2007), Wang et al. (2018) and Zhou and Gao (2020). Bagan and Yamagata (2012) studied how Tokyo became the world's largest megacity using remote sensing data and census data.

As a typical case of the world's largest cities, chronic traffic jams and commuting hell have been a persistent feature of Tokyo since 1960s. Tokyo has a good transportation network, which connects the urban and suburban locations, and enables the city population to commute long distances (Nozawa and Higuchi 2001). Tokyo is the capital of Japan and the center of politics, economy, imperial family, and media; it is unlike other capitals that separate political functions from the economic zones like Canberra in Australia, Brasilia in Brazil, and Washington DC in the United States. Many companies have their headquarters concentrated in Tokyo because they 
think that it is more advantageous for their business to be based in Tokyo where central ministries and agencies are situated. While the concentration in Tokyo is highly convenient, the problem of over concentration in metropolitan Tokyo has been pointed out by several studies over concerns to maintain sustainability in the region. Decentralization, as stated in the monograph of Hein and Pelletier (2006) and Mochida (2008), is one a key governmental policy that has been emphasized for reducing the concentration within the metropolitan Tokyo area. The expansion of Tokyo as a city was not due to administrative control, but rather due to the economic activities of the private sector accompanying the overconcentration of Tokyo. Several urban policies have been implemented, but population concentration surpasses all the regulations (Omura 2010).

Tokyo metropolitan area is divided into three parts: central Tokyo, suburbs along railways, and suburbs distant from railways. Each area has a role with its own special characteristics along with railway line and stations. Tokyo's 23 wards are considered as central Tokyo. The study of the development of the urban fringe of Tokyo metropolitan area has attracted great attention, since the sustainable rural systems are key concepts of urban development and new perspectives, such as curbing the extensional expansion of urban areas and the need for compact urban development (Li and Monzur 2018; Kikuchi 2008; Yokohari et al. 1994).

A large volume of studies exist on Tokyo's urban structure and planning; however, studies on spatial and temporal land price distributions in Tokyo are few. This research tends to analyze the spatial structure of Tokyo land prices with its temporal variation. The next subsection describes the study area and data used for this research. The findings provide helpful suggestions for the planning of sustainable urban form and development of Tokyo.

\subsection{The data}

Despite the existence of transaction data on housing markets, we focus on the estimation of a spatial hedonic land price function. The reason behind this is as follows. First, the official land prices provided by the Ministry of Land, Infrastructure, Transport and Tourism (MLIT) are open to the public and known to be a reliable long-term statistics database. Acquiring such high-quality transaction data on the housing market is difficult and of limited use. Second, land prices are the primary driving force of housing prices and constitute the real estate property of an agent. Third, determining the factors for land prices can provide useful information on fundamental differences among regions, which are considered to be the sources of price polarization and dispersion. Finally, since transactions of housing markets are highly heterogeneous, transaction prices may have sampling bias as discussed in Gatzlaff and Haurin (1998) and Fisher et al. (2003). By conducting year-on-year analyses of official land prices, it is possible to figure out how the land price polarization and dispersion progress in Tokyo.

We use the "official land prices" published annually by MLIT, which are the most commonly used indicators of land prices in Japan. Its main purpose is to provide a 
price index for transactions of general land and give the standard acquisition price of public utility land, regularized by the national land utilization law.

The official land prices are based on a fixed-point observation. However, because the survey points are changed every year (with some addition and removal), it is difficult to monitor the land price of the same point over a long period. It has also been pointed out that land transactions are both locally and spatially distributed, and market participants do not always provide information on the land they are interested in. For this reason, constructing and implementing statistical models that are reflected in spatio-temporal relationships is important for analyzing the spatial patterns of data. In this study, we shed light on changes in geographical and environmental factors in the estimated land price function using the official land prices in Tokyo.

The 2021 official land prices were obtained from a total of 26,000 sample points distributed across all 47 prefectures of Japan. Of this total, 20,559 points were located in urban areas, 1381 points in urbanization control areas, 4042 points in other city planning areas, and 18 points in areas outside the city planning areas. Of the 2602 points in Tokyo, 1542 points were in residential areas, which are the focus of this study, excluding the Tokyo Islands. We used a total of 43,537 points in the Tokyo residential areas from 25 years between 1997 and 2021.

To consider the influence of the bubble economy period and the years after its collapse, we used the official land prices of residential areas on January 1st of every year between 1997 and 2021 to perform spatial statistical analysis of the residuals of the land prices model. The explanatory variables were selected as follows: the access index of the target points, the distance to the closest major station, front road width, floor area ratio, and acreage (land area) of the target area. In addition, the presence or absence of gas and sewerage facilities were added as dummy variables. To estimate the land price model, all variables, except for the floor-area ratio and dummy variables, were transformed to logarithmic values. Table 1 summarizes a list of explanatory variables and their overview.

Table 2 shows the summary statistics of the access index ( $\mathrm{min})$, distance from the closest station (m), front road width (m), and land area $\left(\mathrm{m}^{2}\right)$ as of 2021 . The access index represents the convenience of access to the closest station. For this variable, we used the average travel time from the station closest to the six major stations, Shinjuku, Ikebukuro, Tokyo, Shibuya, Ueno, and Shinagawa. Data on the distance from station, front road width, and land area were obtained from official land price announcements published by the MLIT. As shown in Table 2, the average time from Tokyo to each terminal station was $43 \mathrm{~min}$, the average distance from the closest station was $1060 \mathrm{~m}$, the average front road width was $6.0 \mathrm{~m}$, and the average land area was $211 \mathrm{~m}^{2}$. In addition, the skew to the right distributions of the distance from the closest station, front road width, and land area was observed with several large outliers.

Figure 1 shows the average annual income by Tokyo municipality. Using the "Basic Survey on Wage Structure" released by the Ministry of Health, Labor and Welfare, the annual income (tax excluded) for each municipality in Tokyo in 2020 was calculated. The land price and the average annual income are highly correlated when compared with the distinction. These findings are consistent with various studies including Tiwari (2000), Sutton (2002) and Chen et al. (2007). The high average 
Table 1 List of variables and their overviews

\section{Overview}

Dependent variable official land price $\left(\mathrm{yen} / \mathrm{m}^{2}\right.$ ) Official land price data for residential areas between 1997 and 2021

Explanatory variable

1. Access index (min)

Average commute time from the closest station to six major stations of Tokyo by the average number of users

2. Distance from station (m)

Distance from the closest station

3. Front road width $(\mathrm{m})$

In case of two or more roads, the widest ones were adopted

4. Land area $\left(\mathrm{m}^{2}\right)$

5. Average annual income (yen)

Average annual income by municipality, divide by 1000

6. South-headed dummy

7. Driveway dummy

Front road is located southeast, south or southwest 1, other directions 0

8. Gus equipment dummy

Front road is a driveway 1 , if not 0

9. Sewerage dummy

Present 0, Absent 1

10. Low-rise residence dummy

Present 0 , Absent 1

Low-rise exclusive residential districts of categories 1 or 2 are set at 1 , others 0

11. Residential/Quasi-residential dummy

Residential/quasi-residential districts of categories 1 or 2 are set at 1 , others 0

12. Quasi-fire prevention dummy

Quasi-fire prevention districts 1, others 0

13. Fire prevention dummy

Fire prevention districts 1 , others 0

Table 2 Summary statistics for access index, distance from the closest station, front road width, and land area in 2021

\begin{tabular}{lllll}
\hline & Access index & Distance from station & Front road width & Land area \\
\hline Sample size & 1542 & 1542 & 1542 & 1542 \\
Average & 42.556 & 1063.184 & 6.038 & 211.427 \\
Standard error & 0.4575 & 24.081 & 0.09200 & 8.533 \\
Median & 39.833 & 800 & 5.4 & 154 \\
Mode & 61.067 & 1200 & 6 & 165 \\
Standard deviation & 17.964 & 945.612 & 3.613 & 335.089 \\
Kurtosis & -0.5088 & 14.596 & 13.051 & 167.101 \\
Skewness & 0.4179 & 3.208 & 22.697 & 10.707 \\
Max & 106.966 & 8400 & 40 & 7320 \\
Min & 8.526 & 100 & 2 & 47 \\
\hline
\end{tabular}

annual income of the eastern part of Tama, which is adjacent to the central part of the 23 wards, is also reflected to the corresponding high land prices.

Dummy variables used in this study include the south-headed, driveway, gas equipment, sewerage, low-rise residence, residential/quasi-residential, quasi-fire 


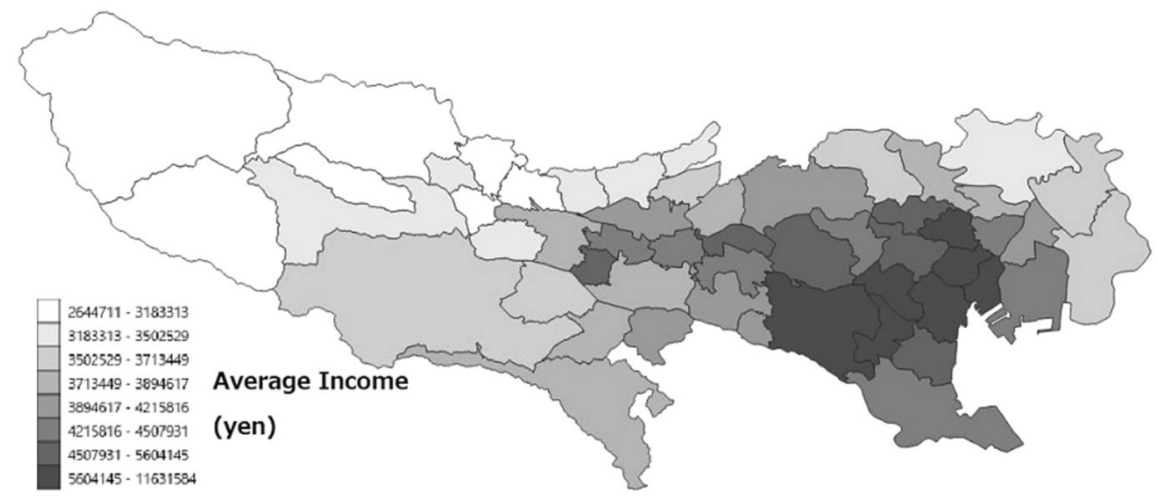

Fig. 1 Average annual income by Tokyo municipality in 2020

prevention, and fire prevention. These data were obtained from the information published along with the official land price data released by the MLIT. If the regression coefficient of the "South-Headed Dummy" is positive, then good sun exposure increases land prices. For the "Driveway Dummy," if the front road is a driveway, then the relationship between land prices in the different regions is complicated; hence, if the regression coefficient is negative, land prices reduce. For the "Gas Equipment Dummy" and "Sewerage Dummy," if their regression coefficient is negative, it means that the respective area requires infrastructure development; therefore, the land prices drop. The "Low-Rise Residence Dummy" represents the low-rise exclusive residential districts of categories 1 or 2, a common designation in the so-called "upscale residential areas." Therefore, if the regression coefficient for the low-rise residence dummy variable is positive, the respective area is considered to have higher land prices than other use districts. The "Residential/Quasi-Residential Dummy" is designated near stations and along large roads, representing residential and quasi-residential districts of categories 1 or 2 . The building coverage ratio and floor area ratio are set higher than those in other use districts, and the range of building use is wide. Therefore, if the regression coefficient for the Residential/Quasi-Residential Dummy variable is positive, the land price is judged to be higher than in other regions because of the preference for convenient transportation and commercial use.

The "Use district dummy" was based on the medium-to-high rise exclusive residential districts of categories 1 or 2. The "Quasi-Fire Prevention Dummy" and "Fire Prevention Dummy" represent quasi-fire prevention districts and fire prevention districts, respectively, where building restrictions such as fireproof building and quasi-fireproof building are applied, which normally increase the construction costs. However, at the same time, because it improves safety, the land price of the corresponding region is not necessarily low. If the regression coefficient for "Quasi-Fire Prevention Dummy" and "Fire Prevention Dummy" variables is positive, it is concluded that the land prices are high due to safety 


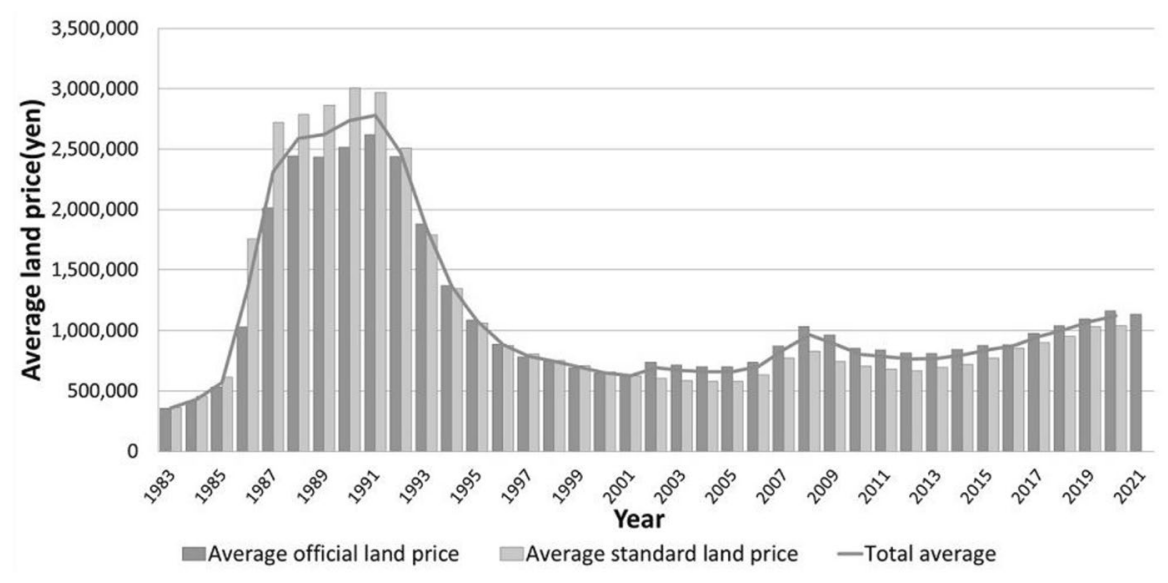

Fig. 2 Time series plots for average land prices from 1983 to 2021

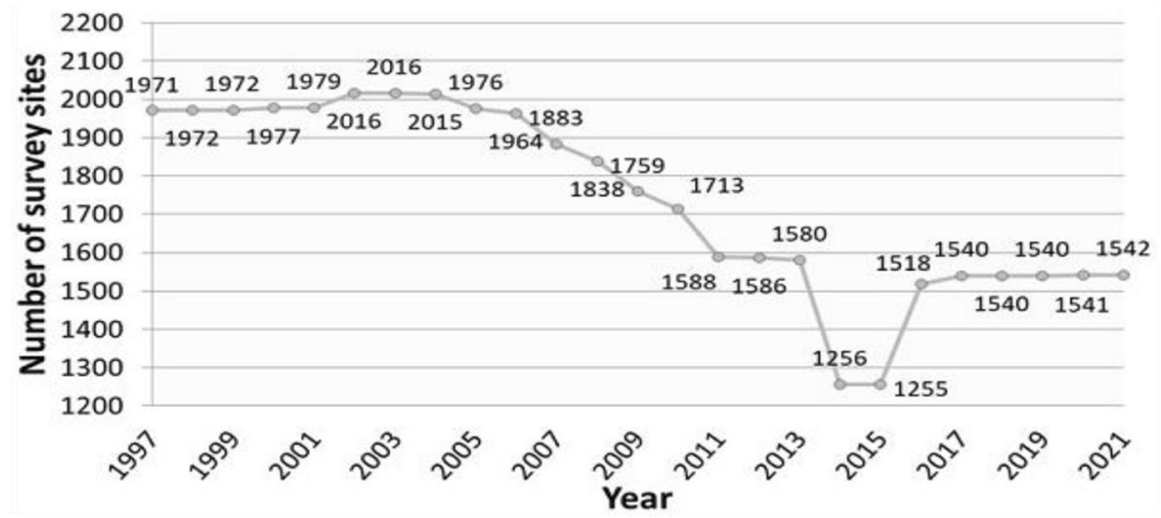

Fig. 3 Time series plots of numbers of survey sites from 1997 to 2021

restrictions; if it is negative, the land prices are considered low because of the decision to avoid increases in construction costs.

Figure 2 plots the transition of the average standard/benchmark land prices in all use districts in Tokyo over 39 years, between 1983 and 2021. During the bubble economy between 1986 and 1991, the real estate prices rose rapidly, but they dropped sharply when the bubble burst. Although the prices rose momentarily from 2006 to 2008 , they entered a downward trend again due to the 2008 financial crisis. More recently, the prices have sustained a gradual upward trend for seven consecutive years, about two years ahead of the national land price average. The average land price of 2021 fell for the first time in eight years due to the coronavirus outbreak. 


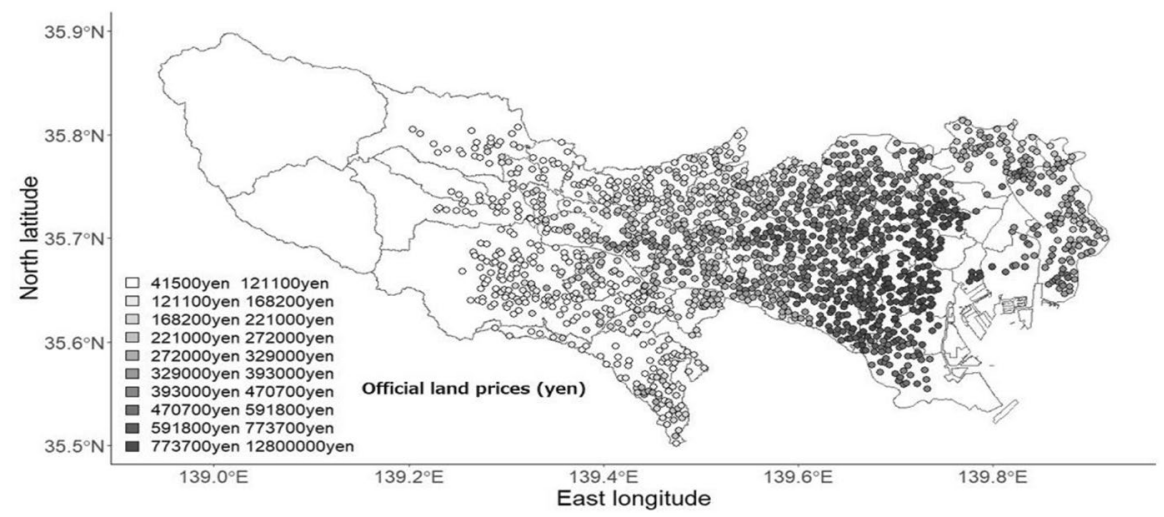

Fig. 4 Spatial distribution of Tokyo official land prices in 2021

Figure 3 shows the transition of the number of survey sites in residential areas in Tokyo5 (excluding the Tokyo Islands) between 1997 and $2021^{3}$. Survey sites are examined and changed every year, and those deemed ineligible are replaced. The abnormal price fluctuation during the bubble economy until its collapse taught the importance of identifying land price trends in more detail; as a result, the number of survey sites in the mid-1990s almost doubled compared to that in the 1980s. It stayed close to 2000 sites until around 2005, but it has been gradually decreasing due to the reducing number of real estate appraisers. In 2014, it dropped by more than 20\% from the previous year. However, in the 2016 Official Land Prices, the number of survey sites reached the level before 2013 and has been hovering at about 1500 sites in recent years.

Figure 4 is a spatial distribution of the official land prices in Tokyo residential areas in 2021. The number of official survey sites was 1542 , and the price per square meter varied from 41,500 yen to up to $12,800,000$ yen. The official land prices are higher near the center of the 23 wards, at the center of the city, and decrease concentrically outwards. However, the official land prices in the 23 wards are not necessarily higher than other areas, as some sites in the cities of Musashino and Mitaka (western Tokyo) are more expensive than those in Adachi, Katsushika, and Edogawa Wards in northeast Tokyo. The number of official points and their position are highly biased by region. The histogram of official land prices in Fig. 5 shows that the land price of some areas is very high, forming a right-skewed distribution.

To see how inequality changes in land price distribution in Tokyo, we plot a Lorenz curve for every six years after 2001 in Fig. 6. The Gini indexes are also shown in the figure. We can see that spatial inequality increases as time

\footnotetext{
${ }^{3}$ Here, "residential districts" refer to seven types of districts: low-rise exclusive residential districts of categories 1 or 2, medium-to-high rise exclusive residential districts of categories 1 or 2 , residential districts of categories 1 or 2 , and quasi-residential districts.
} 


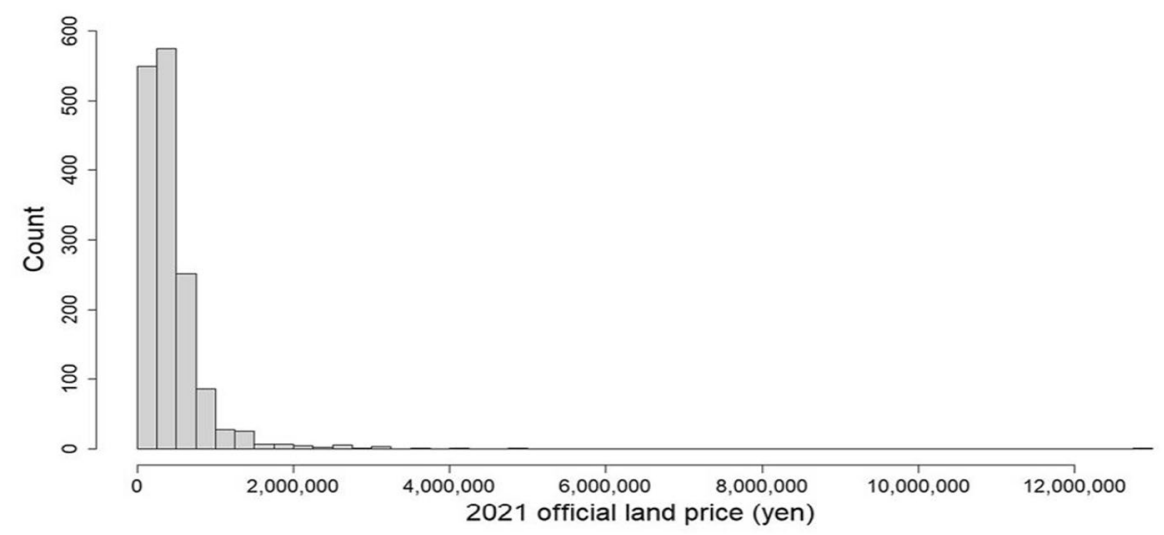

Fig. 5 Histogram of Tokyo official land prices in 2021

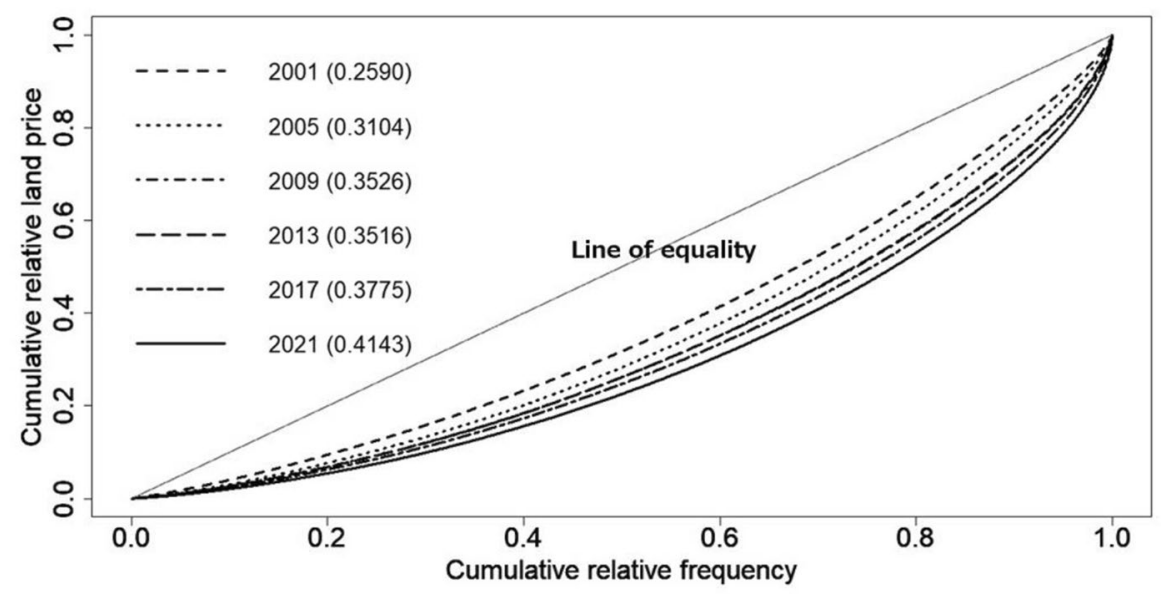

Fig. 6 Plots of Lorenz curve together with Gini indexes in Tokyo land prices for 2001, 2005, 2009, 2013, 2017, 2021

progresses. It is noted that the Japanese Gini index after income redistribution is around 0.372 in 2017, which is similar to the value of the Tokyo land price distribution. Figure 7 shows the spatial distribution of the average rate of changes in land prices in Tokyo. As can be seen from this figure, the rate of changes in land prices appears in the clusters where central Tokyo remains high compared with other areas such as western Tokyo. We found that the land price dispersion occurs in regional clustering. Notice that the average official land price in the target area is 412,200 yen per square meter in 1997 and 432,900 yen in 2021, but the standard deviation was 182,900 yen in 1997 and 506,000 yen in 2021. These simple 


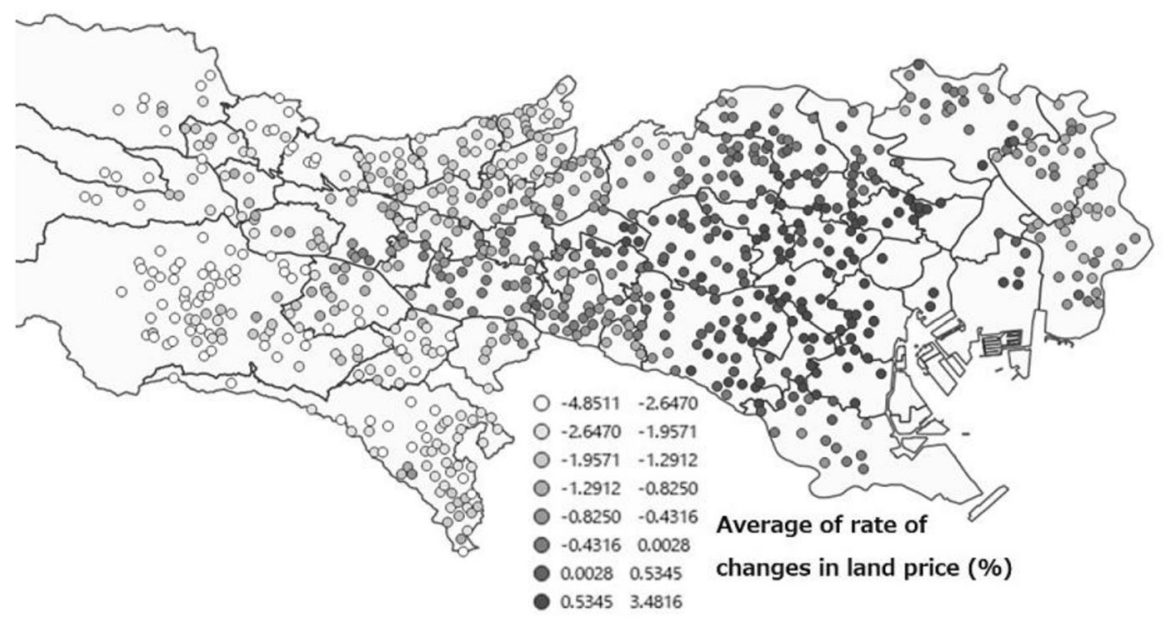

Fig. 7 Spatial distribution of the average of the rate of changes in Tokyo land prices

facts also indicate that spatial inequality and dispersion increased in Tokyo in the last two decades.

\section{Methodology}

In this section, we briefly describe the model and the method for parameter estimation. The universal kriging approach used in this study is explained in detail in (Cressie (1993), Chapter 3). There are several reasons why we chose the universal kriging approach. First, the method of kriging has been systematized, as in Cressie and Huang (1999). A method for extending it to spatio-temporal data is theoretically being established. Further, according to Gneiting (2002), spatiotemporal kriging from an indivisible spatiotemporal variogram takes into account the interaction between time series and space. The market value of land tends to have a series of correlation in both time and space directions. By modeling the covariance structure in spatial kriging, it is possible to make predictions with higher accuracy than the conventional method.

The logarithmic land price at discrete sites $\boldsymbol{s}_{i}(i=1,2, \ldots, n)$ is denoted by $Y_{t}\left(\boldsymbol{s}_{i}\right)$ for time $t=1,2, \ldots, T$. It is assumed that official land prices can be expressed as the asset characteristics of these sites that are expressed as $m_{t}\left(\boldsymbol{s}_{i}\right)=\boldsymbol{X}_{t}\left(\boldsymbol{s}_{i}\right) \boldsymbol{\beta}_{t}$, and the error term. For the land price process, we consider a continuous spatial process $\left\{Y_{t}(s): s \in D\right\}$, where $D$ is the target region. With universal kriging, $Y_{t}(s)$ can be expressed as follows:

$$
Y_{t}(\boldsymbol{s})=\boldsymbol{X}_{t}(\boldsymbol{s}) \boldsymbol{\beta}_{t}+u_{t}(\boldsymbol{s}) \text {. }
$$

Assuming first- and second-order spatial stationarity on the residual of universal kriging $u_{t}\left(\boldsymbol{s}_{i}\right)$ and distance $\|\boldsymbol{h}\|$ from $\boldsymbol{s}_{i}$, the spatial variogram is defined as follows:

$$
2 \gamma_{t}(\boldsymbol{h})=\operatorname{Var}\left[u_{t}\left(\boldsymbol{s}_{i}+\boldsymbol{h}\right)-u_{t}\left(\boldsymbol{s}_{i}\right)\right] .
$$


Here, we assume the first- and second-order intrinsic stationarity for the difference between two arbitrary sites, that is,

$$
E\left[u_{t}\left(\boldsymbol{s}_{i}+\boldsymbol{h}\right)-u_{t}\left(\boldsymbol{s}_{i}\right)\right]=0 .
$$

We also assume that the residual process $u_{t}(\boldsymbol{s})$ is independent of the time points, that is,

$$
\begin{aligned}
& \operatorname{Cov}\left[u_{s}\left(s_{i}\right), u_{t}\left(s_{i}+\boldsymbol{h}\right)\right]=0, \quad \forall s_{i}, \\
& \boldsymbol{h} \in D, \quad \text { for } t \neq s .
\end{aligned}
$$

If we assume the second-order stationarity of the residuals for spatial processes, then the covariance function is defined as:

$$
\begin{gathered}
C_{t}(\boldsymbol{h})=\operatorname{Cov}\left[u_{t}\left(\boldsymbol{s}_{i}\right), u_{t}\left(\boldsymbol{s}_{i}+\boldsymbol{h}\right)\right]=E\left[\left\{Y_{t}\left(\boldsymbol{s}_{i}\right)-m_{t}\left(\boldsymbol{s}_{i}\right)\right\}\right. \\
\left.\left\{Y_{t}\left(\boldsymbol{s}_{i}+\boldsymbol{h}\right)-m_{t}\left(\boldsymbol{s}_{i}+\boldsymbol{h}\right)\right\}\right], \quad \forall \boldsymbol{s}_{i}, \boldsymbol{h} \in D,
\end{gathered}
$$

The relationship between the spatial variogram and covariance function is expressed as $\gamma_{t}(\boldsymbol{h})=C_{t}(\mathbf{0})-C_{t}(\boldsymbol{h})$. We call $\gamma_{t}(\boldsymbol{h})$ a semi-variogram.

There have been various proposals for theoretical models of spatial variograms and corresponding covariance functions. The shape of a spatial variogram is determined by three parameters: nugget, sill, and range. The nugget is the semivariance when the distance between points is close to $\mathbf{0}$, the sill represents the variance of a spatial process, and the value obtained by subtracting the nugget from the sill is called the partial sill. The range is the minimum $\boldsymbol{h}$ for the correlation between $u_{t}\left(\boldsymbol{s}_{i}\right)$ and $u_{t}\left(\boldsymbol{s}_{i}+\boldsymbol{h}\right)$ is 0 .

In this study, the following spherical model was adopted as the theoretical variogram model:

$$
\gamma_{t}(\boldsymbol{h})= \begin{cases}\tau_{t}^{2}+\sigma_{t}^{2} & \left(\text { if }\|\boldsymbol{h}\|>1 / \phi_{t}\right), \\ \tau_{t}^{2}+\sigma_{t}^{2}\left[\frac{3}{2} \phi_{t}\|\boldsymbol{h}\|-\frac{1}{2}\left(\phi_{t}\|\boldsymbol{h}\|\right)^{3}\right] & \left(\text { if } 0<\|\boldsymbol{h}\| \leq 1 / \phi_{t}\right), \\ 0 & \text { (otherwise) } .\end{cases}
$$

where $\tau_{t}^{2}$ is a nugget, $\sigma_{t}^{2}$ is a partial sill, $\tau_{t}^{2}+\sigma_{t}^{2}$ is a sill, and $1 / \phi_{t}$ is the range.

Assuming that the isotropy assumption holds in the spatial process, the empirical semi-variance in interval $h_{r}, \gamma_{t}^{*}\left(h_{r}\right)$, is given by

$$
\gamma_{t}^{*}\left(h_{r}\right)=\frac{1}{\# N_{r}} \sum_{(i, j) \in N_{r}} \gamma_{t, i, j}^{*}(\boldsymbol{h})=\frac{1}{2 \# N_{r}} \sum_{(i, j) \in N_{r}}\left[\hat{u}_{t}\left(\boldsymbol{s}_{i}\right)-\hat{u}_{t}\left(\boldsymbol{s}_{j}\right)\right]^{2},
$$

where $N_{r}$ is a set of sample pairs satisfying $\left\|\boldsymbol{s}_{i}-\boldsymbol{s}_{j}\right\| \approx h_{r}$, and $\# N_{r}$ is the number of sample pairs satisfying $\left\|\boldsymbol{s}_{i}-\boldsymbol{s}_{j}\right\| \approx h_{r} . \gamma_{t, i, j}^{*}$ measures the dissimilarity between sites $\boldsymbol{s}_{i}$ and $s_{j}$. To estimate the empirical variogram using the observed data, we use the Cressie-Hawkins robust estimator (Cressie and Hawkins 1980): 


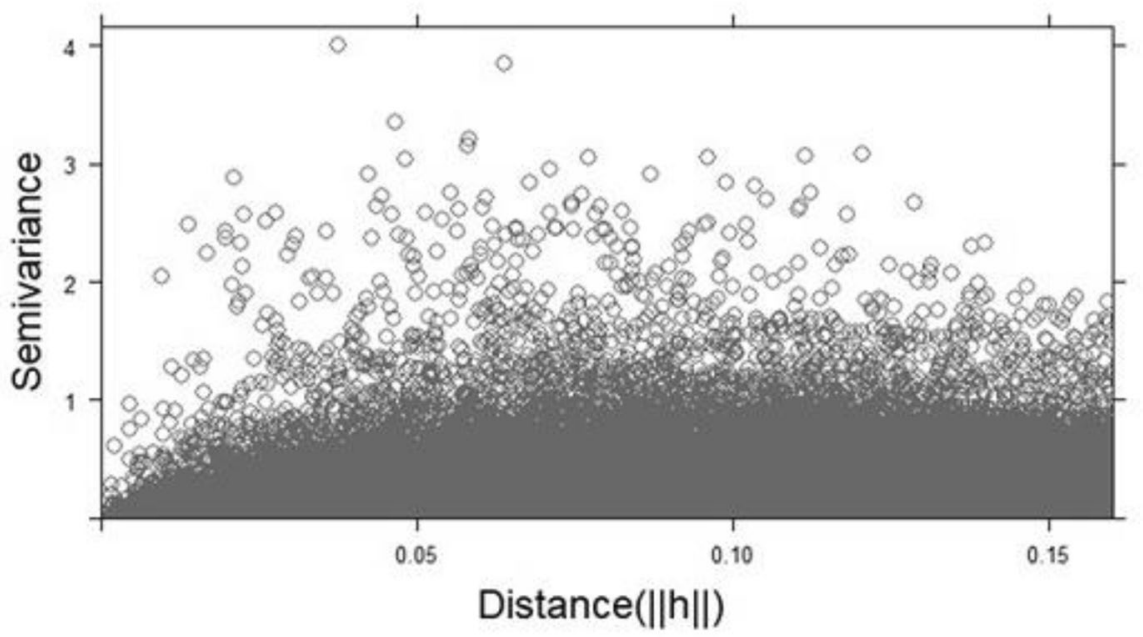

Fig. 8 Variogram cloud of logarithmic Tokyo Official Land Prices in 2021

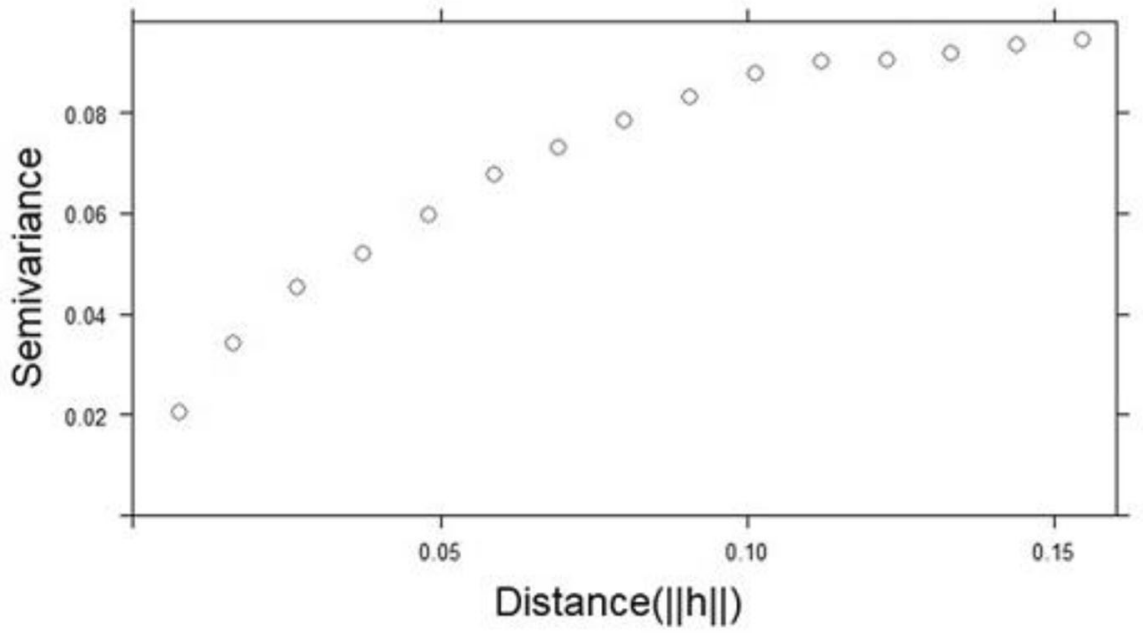

Fig. 9 Plots of the empirical variogram in 2021

$$
\gamma_{t}^{*}\left(h_{r}\right)=\frac{\frac{1}{2}\left\{\frac{1}{\# N_{r}} \sum_{(i, j) \in N_{r}} \sqrt{\left|\hat{u}_{t}\left(\boldsymbol{s}_{i}\right)-\hat{u}_{t}\left(\boldsymbol{s}_{j}\right)\right|}\right\}^{4}}{0.475+\frac{0.494}{\# N_{r}}},
$$

which is found to be robust to the outliers.

By plotting the dissimilarity as a function of distance $h$, we obtained a variogram cloud. Figures 8 and 9 show the variogram cloud and the empirical variogram of the 
regression residuals of the 2021 official land price data. In Fig. 8, since the semivariance in the vertical axis indicates the measures of dispersion of all observational points and the horizontal one represents corresponding distances, we see that spatial dispersion exists in a certain amount. This dispersion can be measured by the variogram parameters as the nugget, sill, and range. From Fig. 9, we see that the larger the semi-variance value, the larger the dissimilarity between the observation points. From the variogram cloud, we can see that as the distance between the observation points increases, the semi-variance also increases, and its variation has a non-linear relationship with the distance. In addition, the empirical variogram shows that as the distance increases, the dissimilarity of the observed values converges to a constant value.

The vector, of the parameters of the theoretical variogram is denoted by $\boldsymbol{\theta}_{t}=\left(\tau_{t}, \sigma_{t}, \phi_{t}\right)^{\prime}$, and the parameters of the theoretical variogram are estimated using the nonlinear weighted OLS method introduced by Cressie (1985). Here, the theoretical and empirical variograms are expressed as $\gamma_{t}$ and $\gamma_{t}^{*}$, respectively.

$$
\hat{\boldsymbol{\theta}}_{t, \mathrm{NWLS}}=\operatorname{argmin}_{\boldsymbol{\theta}_{t}} \sum_{r=1}^{R}\left[\operatorname{Var}\left\{\gamma_{t}^{*}\left(h_{r}\right)\right\}\right]^{-1}\left[\gamma_{t}^{*}\left(h_{r}\right)-\gamma_{t}\left(h_{r} \mid \boldsymbol{\theta}_{t}\right)\right]^{2} .
$$

Here the inverse variance weighting is applied with the following approximation:

$$
\operatorname{Var}\left\{\gamma_{t}^{*}\left(h_{r}\right)\right\} \approx 2 \gamma_{t}\left(h_{r} \mid \boldsymbol{\theta}_{t}\right)^{2} / \# N_{r}
$$

To estimate the regression coefficients and variogram parameters in universal kriging, we used the iterative method known as iterative re-weighted generalized least squares (IRWGLS), which was introduced by Schabenberger and Gotway (2005).

\section{Spatial variogram estimation and its transition}

In this section, we investigate the land price model using the official land prices in Tokyo. Since the official land prices of residential areas in Tokyo vary drastically according to the survey sites and the covariance structure of the residuals of the land price model has regional characteristics, the assumption of second-order spatial stationarity does not hold for all regions. For this reason, we apply a cluster analysis that divides the data into four regions using a hierarchical clustering method with Ward's linkage. For this, we calculate the distances between municipalities by using the average and variance of the land prices of each municipality. In this study, only the mean and variance of land prices were used for clustering. There is no relationship between clustering and the economic trends of municipalities.

Figures 10 and 11 show a dendrogram of the hierarchical clustering analysis and the map of the resulting four clusters in Tokyo, respectively. The town of Okutama and the village of Hinohara (the areas located West and municipality names are missing). They were excluded because the official land prices of their residential areas had not been evaluated in the analysis period. The southeast is a region that includes Chiyoda, Minato, and Chuo Wards, the so-called heart of the capital that 


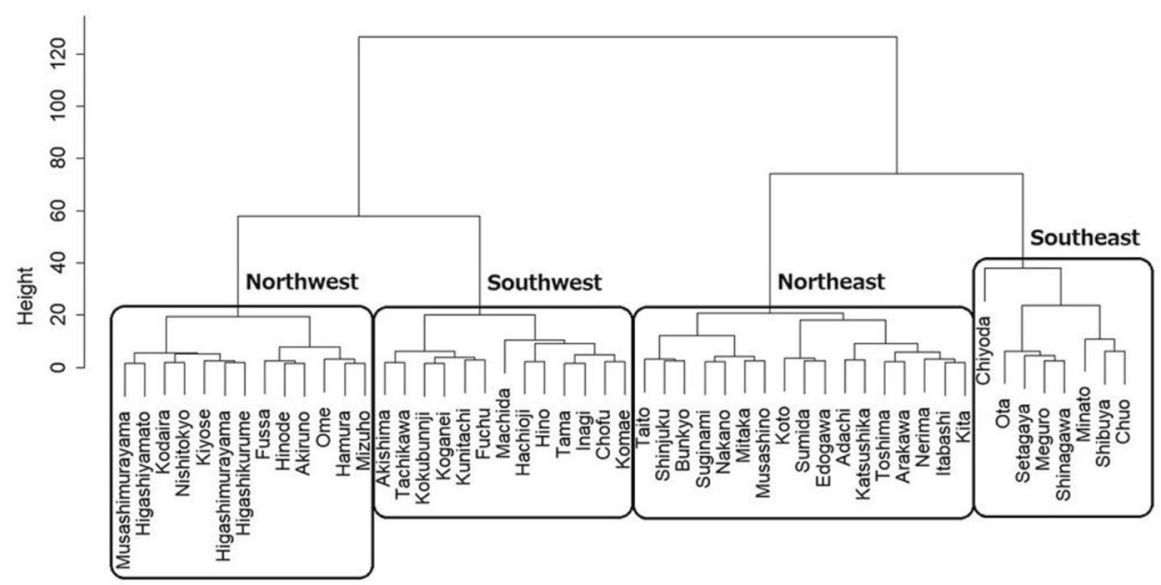

Fig. 10 Dendrogram of the Tokyo Municipalities

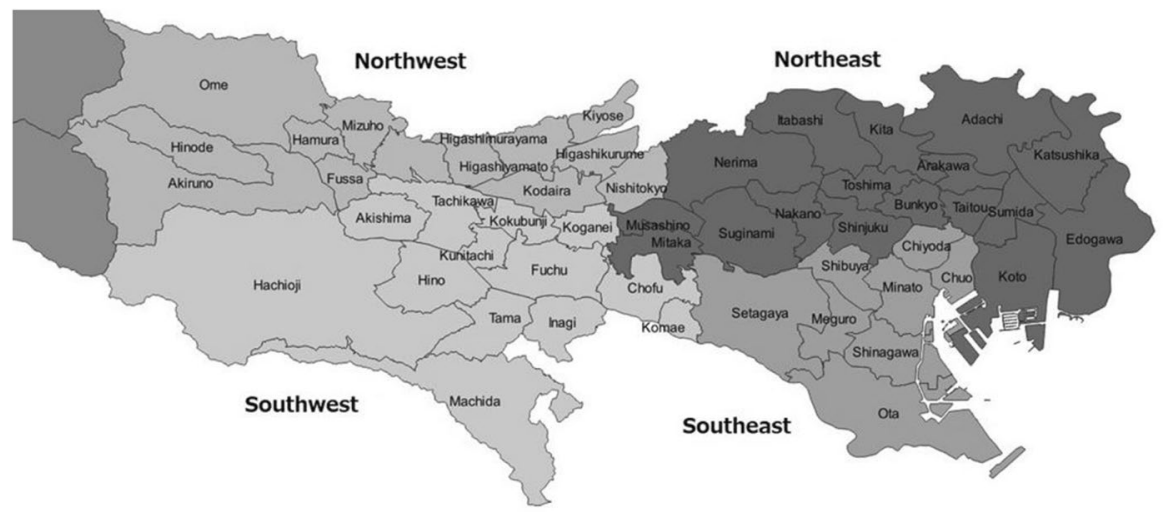

Fig. 11 Spatial clustering of the Tokyo Municipalities dividing into four regions

concentrates government offices, commerce, and head office of large corporations, as well as the "Jonan district," which contains popular high-class residential areas such as Shinagawa, Meguro, and Ota Wards. The northeast is a region that includes the eastern part of the 23 wards like Shinjuku, Toshima, and Bunkyo Wards, which still preserve the atmosphere of a "sub-center" and "downtown" aimed at decentralizing central functions, as well as the cities of Musashino and Mitaka, which, despite not being included in the 23 wards, are among the most desired cities to live in according to recent surveys. The regional transportation in the southwest, which includes the Minamitama (South Tama area) and the southern Kitatama (South part of North Tama area), became remarkably more convenient with the recent urban redevelopment. Hachioji has the largest population among all municipalities in Tokyo, and the city of Tama has a remarkable population increase rate. The northwest includes the 
Nishitama area and northern Kitatama area, and the plains and hills are developing into Tokyo's commuter towns. It is an area that features rare landscapes in Tokyo, such as fields, hills, and mountains.

To detect a global trend in the four regions, we chose five explanatory variablesaccess index, distance from the closest station, front road width, land area, and average annual income-at five different times, i.e., six and twelve years before and after the 2008 financial crisis (1997, 2003, 2009, 2015, and 2021). We performed the Kruskal-Wallis $H$ test on all these years. As a result, for the access index and front road width, the null hypothesis that the median of all five-time points is the same cannot be rejected in any of the four regions with a significance level of 5\%. In the distance to the closest station, a significantly negative trend was observed in the northeast area. Presumably, this is due to the extension of railroad lines and construction of new ones, such as the Fukutoshin Line (No. 13, opened in 2008), as well as changes in official price areas targeting standard land. In the floor area ratio, the null hypothesis could not be rejected in the southeast and northeast, but a positive trend was observed in the southwest and northwest. This may be due to changes in land regulations due to the development of the "Tama Site Development Basic Plan" and the replacement of the standard area that followed. In the land area, a negative trend was verified in the northeast and southwest regions. This is also attributed to changes in land price data caused by changes in the definition of standard land over time.

Table 3 shows the OLS estimates of 2021 land prices. Recall that the OLS methods constitute the global model that has non-spatial structures. The numbers in parentheses are the standard error. Some regions do not have Gas Equipment Dummy or Sewerage Dummy parameters because those facilities had already been built in the entire official target area before 2021, while others do not have the Fire Prevention Dummy because no fire prevention district was selected as a target area for the official land prices of that year. The characteristics of each region become clear when the respective estimated coefficients are compared to those of Tokyo as a whole. It is possible to identify that the larger regional differences in the parameters of access index, land area, residential/quasi-residential dummy, and quasi-fire prevention dummy exist. The access index coefficient shows that the official land prices in the west have a greater negative impact than those in the east. As for the land area coefficient, the fact that the southeast and northeast have positive coefficients indicates that there is no volume discount effect. Also, the residential/quasi-residential dummy coefficient is negative in the northeast and southwest. This implies that commercial elements do not negatively affect housing preferences in the area. The quasi-fire prevention dummy coefficient has a significant negative impact at $5 \%$ level in the northeast and a significant positive impact at 5\% level in the southwest. From this, it can be inferred that in the northeast, the negative impact of the increase in construction costs caused the official land prices to increase; in the southwest, it was caused by security and safety. This shows that the factors that determine the official land prices are not too different from our intuitive understandings.

Table 4 summarizes the 2021 land prices estimated parameters using the IRWGLS method. Compared to the results of the non-spatial model, the absolute values of the spatial process model estimates are smaller, and the standard error is 


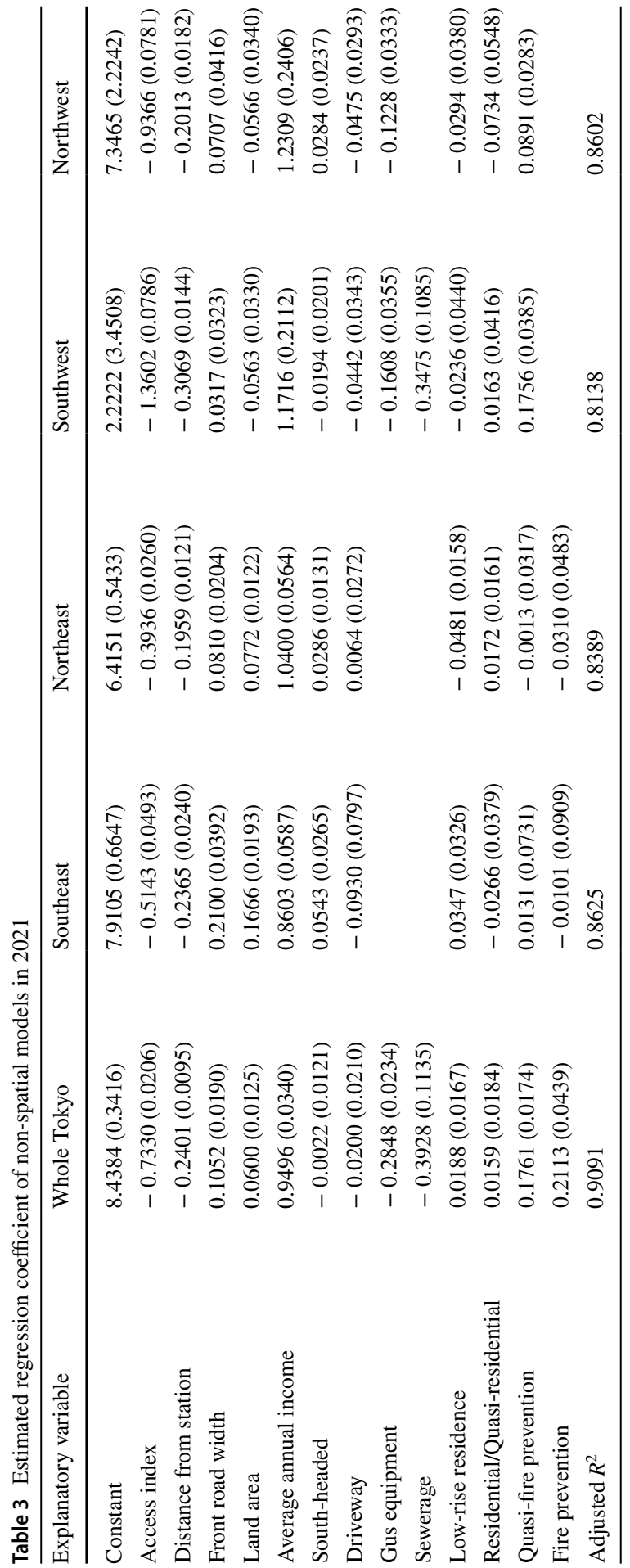




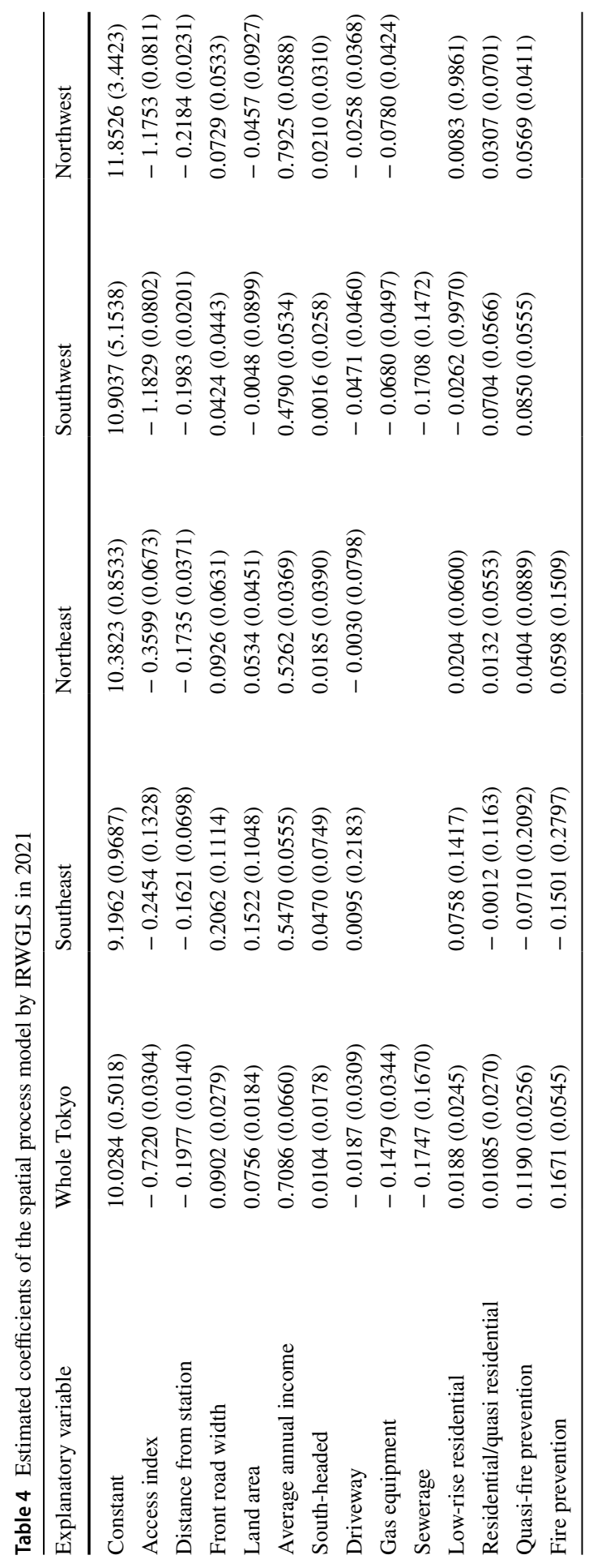




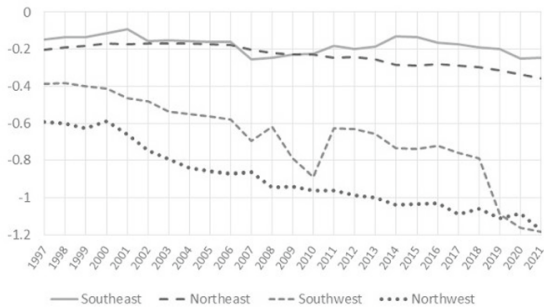

(a) Access Index

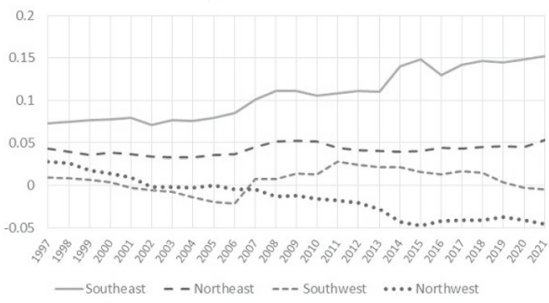

(c) Land Area

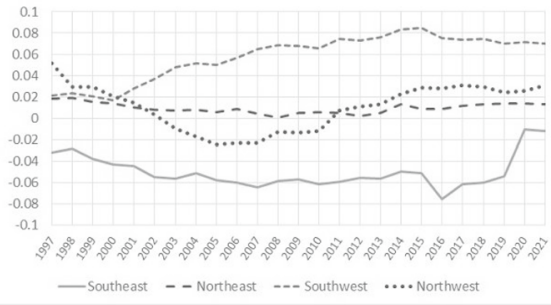

(e) Residential/Quasi-Residential Dummy

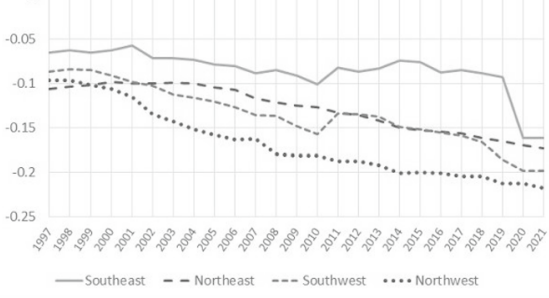

(b) Distance from Station

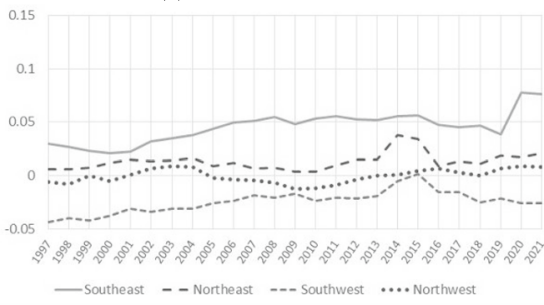

(d) Low-Rise Residential Dummy

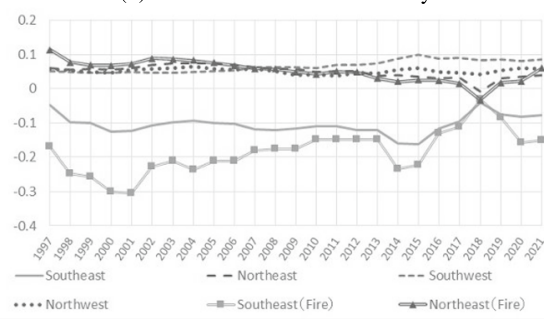

(f) Quasi-Fire/Fire Prevention Dummy

Fig. 12 Transition of the regression coefficients

larger. Compared to Table 3, the estimated coefficient of the low-rise residence dummy in the northeast is no longer significantly negative at the 5\% level. In the northwest, the Residential/quasi-residential dummy becomes positive, and the difference with the official land prices of low-rise exclusive residential districts decreases. In the northwest, the estimated coefficient for the Land Area is smaller than that of the other area. This shows that there is the volume discount effect in the northwest area. Most of the signs of the other coefficients match those of the OLS. Following previous studies, we adopted a spatial variogram with a spherical model and estimated the covariance structure with a valid distance of 6.67 $\mathrm{km}$ in the southeast, $5.56 \mathrm{~km}$ in the northeast, and $8.89 \mathrm{~km}$ in the southwest and northwest.

To see the time-series transition of the estimated coefficients, we provide the following figures and tables. Figure 12 shows the annual changes in the regression coefficients of the access index, distance from the closest station, land area, lowrise residence dummy, residential/quasi-residential dummy, and quasi-fire prevention/fire prevention dummy of the estimated spatial process model. In Table 5, the test results of the null hypothesis of the zero slopes in the linear regression for 
Table 5 Test statistics and its $p$-values for the null hypothesis of no slope in the linear regression with time trend for access index, distance from station, residence dummy, residential/quasi-residential dummy, and quasi fire/fire prevention dummy

\begin{tabular}{|c|c|c|c|c|c|}
\hline Explanatory variable & Tokyo Region & Estimates & $p$-value & $90 \%$ L. B. & $90 \%$ U. B. \\
\hline \multirow[t]{4}{*}{ Access Index } & Southeast & -0.0038 & 0.0003 & -0.0053 & -0.0025 \\
\hline & Northeast & -0.0071 & 0.0000 & -0.0086 & -0.0062 \\
\hline & Southwest & -0.0265 & 0.0000 & -0.0266 & -0.0245 \\
\hline & Northwest & -0.0305 & 0.0000 & -0.0325 & -0.0281 \\
\hline Distance from & Southeast & -0.0029 & 0.0000 & -0.0036 & -0.0019 \\
\hline \multirow[t]{3}{*}{ Station } & Northeast & -0.0033 & 0.0000 & -0.0038 & -0.0030 \\
\hline & Southwest & -0.0039 & 0.0000 & -0.0041 & -0.0039 \\
\hline & Northwest & -0.0058 & 0.0000 & -0.0062 & -0.0053 \\
\hline \multirow[t]{4}{*}{ Land Area } & Southeast & 0.0035 & 0.0000 & 0.0029 & 0.0040 \\
\hline & Northeast & 0.0002 & 0.4378 & -0.0002 & 0.0005 \\
\hline & Southwest & 0.0005 & 0.2209 & -0.0002 & 0.0011 \\
\hline & Northwest & -0.0029 & 0.0000 & -0.0034 & -0.0030 \\
\hline Low-rise & Southeast & 0.0021 & 0.0010 & 0.0016 & 0.0027 \\
\hline \multirow[t]{3}{*}{ Residential Dummy } & Northeast & 0.0011 & 0.0108 & 0.0003 & 0.0018 \\
\hline & Southwest & 0.0027 & 0.0021 & 0.0020 & 0.0032 \\
\hline & Northwest & 0.0000 & 0.9764 & -0.0006 & 0.0006 \\
\hline Residential/ & Southeast & 0.0008 & 0.0588 & -0.0001 & 0.0016 \\
\hline Quasi-residential & Northeast & -0.0002 & 0.0263 & -0.0004 & - 0.0001 \\
\hline \multirow[t]{2}{*}{ Dummy } & Southwest & 0.0024 & 0.0000 & 0.0017 & 0.0027 \\
\hline & Northwest & 0.0005 & 0.2456 & -0.0002 & 0.0014 \\
\hline Quasi-fire/ & Southeast & 0.0003 & 0.5540 & -0.0009 & 0.0015 \\
\hline Prevention & Northeast & -0.0028 & 0.0000 & -0.0035 & -0.0025 \\
\hline \multirow[t]{2}{*}{ Dummy } & Southwest & 0.0013 & 0.0000 & 0.0011 & 0.0014 \\
\hline & Northwest & 0.0004 & 0.1837 & -0.0001 & 0.0008 \\
\hline Fire Prevention & Southwest & 0.0080 & 0.0000 & 0.0057 & 0.0105 \\
\hline Dummy & Northeast & -0.0046 & 0.0000 & -0.0059 & -0.0040 \\
\hline
\end{tabular}

these variables with the explanatory variable time $t$ are summarized. In this table, the " $90 \%$ lower bound" and the " $90 \%$ upper bound" represent the lower and upper bounds of the $90 \%$ confidence interval.

The transition of the coefficients of the access index can be divided into eastern and western Tokyo. That is, in the southeast and northeast, the coefficient remained mostly stable with a small negative value throughout the analysis period; however, in the southwest and northwest, it followed a downward trend. These results indicate that in the western part of Tokyo, the longer time required to access the city center has a stronger negative impact on official land prices every year, and the gap with the eastern part of Tokyo is widening. It can be seen that the coefficient of distance from the closest station is negative in all regions throughout the analysis period, and the three regions other than the central part (southeast) have negatively smaller values than the southeast. In addition, the further an area is from the central area and 
Table 6 Estimated variogram parameters with sum of squared errors of land price model in 2021

\begin{tabular}{lllll}
\hline & Southeast & Northeast & Southwest & Northwest \\
\hline Estimates for spatial variogram & & & & \\
Nugget & 0.0206 & 0.0063 & 0.0077 & 0.0047 \\
Partial sill & 198.2442 & 0.0360 & 0.0377 & 0.0165 \\
Range (km) & 51,190 & 16.47 & 5.39 & 4.88 \\
Mean of squared residuals & & & & \\
Non-spatial model: MSE & 0.0376 & 0.0197 & 0.0438 & 0.0268 \\
Spatial model: MSE & 0.0272 & 0.0084 & 0.0149 & 0.0095 \\
\hline
\end{tabular}

the closest station, the lower the land prices tend to be, and the impact of this coefficient increases every year.

The estimated land area coefficient was positive in eastern Tokyo. This indicates that there is no volume discount effect, and the larger the land area, the more expensive it is. This trend is stronger in the southeast than in other regions, and it increases even further over time, which represents the increasing brand power of certain regions. In contrast, a volume discount effect can be seen in the northwest in the latter half of the analysis period, and it increases gradually. The low-rise residence dummy coefficient shows a positive in the southeast. There is a strong tendency to emphasize the living environment throughout the research period. On the other hand, as for the residential/quasi-reciprocal dummy coefficient, the southeast has a negative value, as regions with strong commercial elements have lower official land prices than other use districts. In contrast, a positive trend can be seen in the southwest, where there is a growing tendency to emphasize convenience and commercial elements. This result can likely be attributed to recent land redevelopment and improvement plans in the Tama area.

Regarding the coefficient of the quasi-fire/fire prevention dummy, the southeast has a negative coefficient and lower prices than other restricted regions. This suggests that this area avoids increases in construction costs due to restrictions, but their impact has been decreasing recently. In addition, a positive trend can be seen in the coefficient of the quasi-fire prevention dummy of the southwest, where, contrary to the southeast, higher levels of safety and security due to restrictions tend to push the official land prices up. It can be seen that, in the first half of the analysis, the fire prevention districts in the southeast lower the official land prices sharply, but that impact lowers in the latter half, and it is almost non-existent in recent years. Moreover, it is possible to see that the other coefficients in the southwest other than the quasi-fire prevention dummy also affect the official land prices less and less over the years.

In panel (d) of Fig. 12, there is a discontinuity in the regression coefficient of the low-rise residence dummy (except in the northwest) of 2014 and 2015, and the same in the regression coefficients of the residential/quasi-residential dummy and fire prevention dummy of the southeast in panels (e) and (f). Presumably, this is the effect of a decrease in the number of official target points in 2014 and an increase 


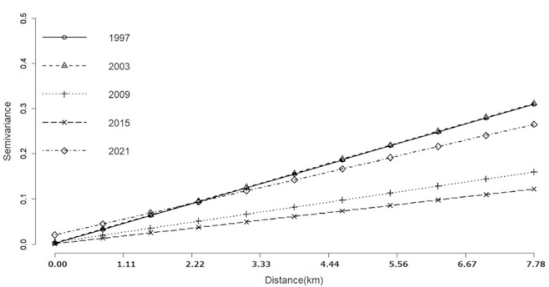

(a) Southeast

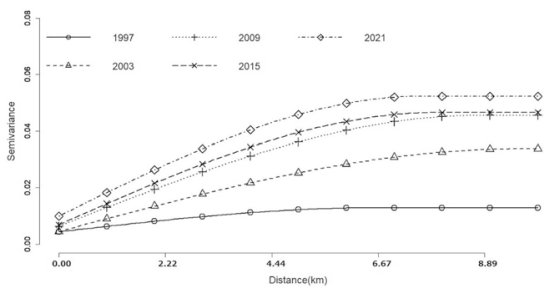

(c) Southwest

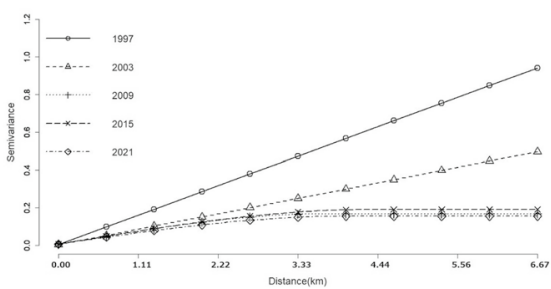

(b) Northeast

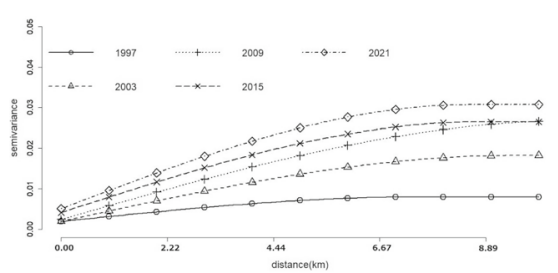

(d) Northwest

Fig. 13 Changes in the variograms for four regions

in 2016. Following the changes in the official land price target areas, there was a jump in the ratio of the number of points in low-rise exclusive residential districts and residential/quasi-residential districts in the southeast. We can see sudden jumps in the regression coefficients of the distance from the closest station, the low-rise residence dummy, the residential/quasi-residential dummy, and the fire prevention dummy of the southwest. This is because the addition of extremely high price site of $12,800,000$ yen per $1 \mathrm{~m}^{2}$ for the land price announcement in 2020 and 2021 .

Table 6 shows the spatial variogram estimates for each of the four regions in 2021 together with the mean of squared error (MSE) of the non-spatial and spatial process models. The range and partial sill values of the southeast are huge. This is because the spatial variogram approached a linear relationship within the valid distance, and the linear part in the spherical model with a small distance difference was fitted to the empirical variogram. Considering that the larger the ratio of sill and nugget effect, or the range, the stronger the spatial correlation of the random fields, it becomes clear that the residuals of the spatial process model of eastern Tokyo have a stronger spatial correlation than the west side. The nugget of the southwest is larger than that of the northeast, which are more than half of 23 wards, where the official land prices are relatively high. Moreover, the MSE of the land price models shows that the MSE of the spatial process model was reduced to about $1 / 2$ to $1 / 3$ of the MSE of the non-spatial model.

Figure 13 shows the variation of the estimated spatial variogram of each region in five different years. Like before, to provide better visualization of the annual changes, we chose the year 2009 (owing to the financial crisis of 2008) and six and twelve years before and after it (i.e., 1997, 2003, 2009, 2015, and 2021). The linear parts show that when the change rate increases, the degree of attenuation of the covariance function also increases. Furthermore, increases in the variogram sill represent increases in the variance of the spatial process of the residuals. In the 


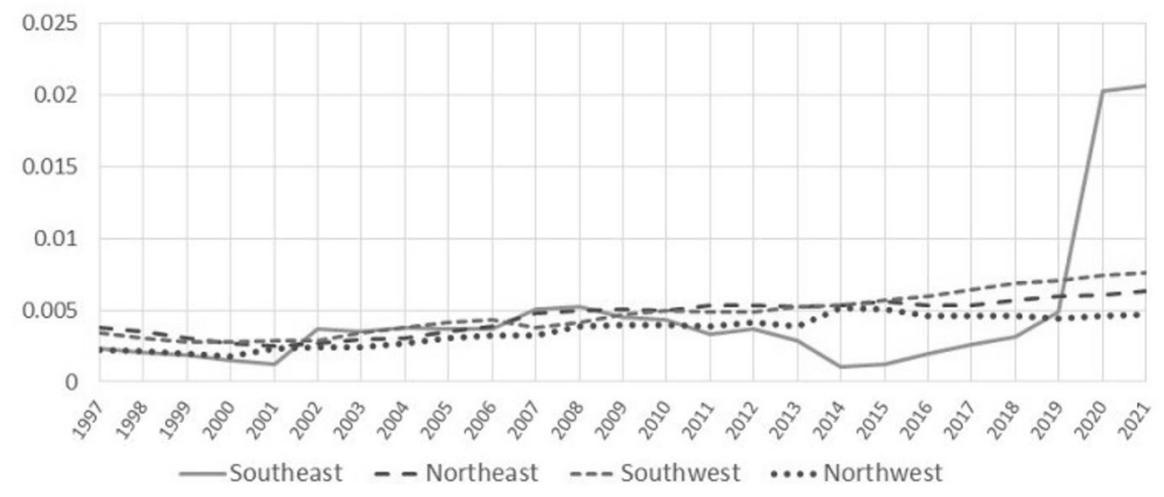

Fig. 14 Nugget effect

Table 7 Test statistics and its $p$-values for the null hypothesis of no slope in the linear regression with time trend for nugget

\begin{tabular}{lllll}
\hline Tokyo region & estimates & $p$-value & $90 \%$ L. B. & $90 \% \mathrm{U} . \mathrm{B}$. \\
\hline Southeast & 0.0003 & 0.0431 & 0.0001 & 0.0006 \\
Northeast & 0.0001 & 0.0000 & 0.0001 & 0.0001 \\
Southwest & 0.0002 & 0.0000 & 0.0002 & 0.0003 \\
Northwest & 0.0002 & 0.0000 & 0.0002 & 0.0002 \\
\hline
\end{tabular}

southeastern part, the decrease in sill after the financial crisis was remarkable, and it can be seen that it has recovered to the level of 1997 in recent years. In the southwest, we can see that the shape of the variogram has remained unchanged since the financial crisis. In contrast, in western Tokyo, we can see that the number of sills continues to increase. As for the parameters of the variograms in 2021, we can see a decrease in variogram sill in the east, whereas it increases in other regions. This indicates that the negative impact on the land prices of the coronavirus outbreak is limited for the east area of Tokyo.

Figure 14 shows the value of the nugget effect of the regression residuals of the spatial process model in Tokyo. Also, Table 7 shows the test result of the rate of change of the linear regression of the nugget. The nuggets of the four regions in Tokyo show a downward trend in the southeast and an overall upward trend in the other regions. As the nugget indicates a local variation of the residuals between two observation points of the land price model, it is empirically known that real estate has strong individuality, and the rise in the nugget indicates that the individual factors of the neighboring land relative to the land prices are becoming stronger, which cannot be explained by the land price model of this analysis. In this context, individual factors include alert areas in hazard maps, the presence of crime, local noises, daylight conditions, and the location of garbage collection points; however, the effect of these variables on land prices is a topic for future research. During the analysis period, the individual factors of neighboring land became stronger in the three regions, except for the southeast, where they became weaker. Regarding the trends in each region, in the early downturn phase of official land prices, the nugget 
is also in a downward trend in all four regions; however, it switched to an uptrend in all regions except the southeast. In addition, the southeast has been on a downward trend regardless of the 2008 financial crisis, but the three other regions do not show a downward trend, not even in the downturn phase of prices that followed. As stated earlier, we can see a jump in the nugget of the southeast from 2018 to 2020 due to the additions of the extremely high land prices of 32,300,000 yen per $1 \mathrm{~m}^{2}$ in 2019 and $12,800,000$ yen per $1 \mathrm{~m}^{2}$ in 2020 .

In the sub-central area of Shinjuku and Ikebukuro and the northeast of cities such as Musashino and Mitaka, the negative impact of the regression coefficients of the Distance from the Closest Station and the impact of individual factors of neighboring lands on the official land prices are becoming stronger. In the southwest, which includes the cities of Fuchu, Kokubunji, Tachikawa, and Hachioji, the regression coefficients of the Access Index and Distance from the Closest Station have a strong negative impact on the official land prices, but it is possible to see that this impact becomes even stronger as time progresses and that the living environment-focused low-rise exclusive residential districts and commerce/convenience-focused residential/quasi-residential districts tend to become more expensive.

In the northwest, which includes west Tokyo and the city of Ohme, the annual changes in the regression coefficients of the Access Index and Distance from the Closest Station are similar to those of the southwest, but the regression coefficient of the Distance from the closest station has a particularly strong negative impact on the official land prices, and it is possible to identify a volume discount effect by the land area in recent years.

In summary, the regression coefficient of the distance from the closest station in the southeast has the smallest negative impact on the official land prices among the four regions. Moreover, the factors that increase prices in low-rise exclusive residential districts are becoming weaker every year, and the regulations of quasi-fire/ fire prevention districts have also been affecting prices less every year. However, the preference for brands has caused the official land prices in the southeast to soar, a tendency that grows stronger every year. Furthermore, the effect of individual factors of neighboring lands, one of the factors that determine land prices, has also decreased. In the northeast, the negative impact of the regression coefficients of the distance to the closest station on the prices has been increasing since the 2008 financial crisis, as well as the impact of individual factors of neighboring lands. In the southwest, the negative impact of the regression coefficients of the access index and distance to the closest station on prices has been increasing. In addition, the official land prices of use districts other than medium-to-high-rise exclusive residential districts tend to be higher. This is a characteristic that is not observed in other regions and is also becoming stronger every year. The fact that quasi-fire prevention regulations elevate official land prices more strongly every year is also characteristic. The strength of the spatial correlation of residuals showed a remarkable uptrend until the 2008 financial crisis, but after that, it switched to a downtrend as the individual factors of the neighboring land increased. In the northwest, the regression coefficients of the access index and distance to the closest station have a stronger negative impact on the official land prices than in the southwest. The impact of the coefficient of the distance to the closest station, in particular, was the largest among the 
four regions. It is the only region in which the volume discount effect can be identified after the 2008 financial crisis. The strength of spatial correlation and the impact of individual factors of the neighboring land have shown a trend similar to that of the southwest. Lastly, regarding the impact of the coronavirus outbreak on the 2021 Tokyo land prices, we can see the decline of the land price, which was similar to the case with 2008 financial crisis, whereas there were little changes in the determinants of land functions. The structural change of the spatial variogram could not be confirmed except in the southeast of Tokyo. In the southeast, the attenuation of the spatial correlation of the regression residuals was confirmed.

The variation of a local population according to the level of convenience in the area is considered one of the reasons for land price polarization. According to the "Reference Material on Official Land Prices" published by the MLIT in 2012, there is a very strong positive correlation between population density in the 47 prefectures in the country and the average official land prices of residential areas, with a correlation coefficient of 0.8950 . In addition, Saita et al. (2016) states that since the collapse of the bubble economy, there is a positive correlation between the workingage population ratio and land prices, and a negative correlation between the elderly population ratio and land prices. In this study, we calculated the daytime population density of municipalities that contain official target sites and found that there is a very strong positive correlation, with a coefficient of 0.7824 , between the official land prices after logarithmic conversion and population density. The first time that the previously mentioned land policies in post-bubble Japan mention population decline (which started in 2008) was in the "Mid-to-Long Term Vision of Land Policies" in 2009, but it was limited to a broad confirmation of the current situation in the entire of Japan, and it did not get to the point of addressing the polarization of land prices. From a different perspective, the concentration of population in urban areas and the depopulation of rural areas have been serious issues in Japan since the late 1960s. Since the Great East Japan Earthquake of 2011, a population policy that proposes shifting governmental functions away from Tokyo has once again gained momentum following the reawakening about the disadvantages of concentrating all of them in the capital. It is also noted that the suburban areas began to face challenges caused by the aging of their residents, and an increase in vacant housing may cause the rise in spatial polarization (Kubo 2020; Kubo and Yui 2020).

\section{Conclusion}

In the wake of the coronavirus outbreak, the official land prices in Tokyo in 2021 have declined whereas other factors such as the determinants of the land functions and spatial structures of the regression residuals have been constant. However, it is still possible to confirm that the spatial correlation of the regression residuals in the southeast including the city center where the average land price is the highest is attenuated, and the influence of the coronavirus outbreak is likely to continue. It is quite possible to see that the impact is in transition. Future land price trends need to be monitored. 
This study investigates how spatial polarization forms and progresses in Tokyo by estimating year-on-year spatial land price models. The spatial dispersion intensifies through the fact that the southeast, which includes the city center and has historically high land prices, was the only one of the four regions whose nuggets showed a downward trend, whereas other regions showed an upward trend. As for the determinants of the land functions, access index together with lowrise exclusive residential districts and medium-to-high-rise exclusive residential districts tend to be expensive, and the acreage also tends to be overpriced, which is in part is attributed to the preference of land brands in the southeast region, which are found to be the source of the spatial polarization.

Based on the transitions in the shape of the spatial variogram, the spatial variance in western Tokyo is gradually becoming larger. This does not influence the volatility of land prices in western Tokyo. In future, it seems feasible to promote urban planning that considers the balance with natural environment conservation, as well as land policies designed for the creation of new land brand power in areas other than the 23 wards.

The spatial correlation of residuals of the spatial model was strong before the 2008 financial crisis but has weakened ever since. The impact of individual factors on neighboring lands is increasing, which are considered to be the background of rising spatial dispersion. Based on the results, the land price trends in the southwest of Tokyo may serve as a reference for anti-polarization measures. It is an area with no significant difference between daytime and nighttime population densities; and judging from the trend of regression coefficients of its spatial process model, there is segregation within use districts.

As a future research topic, it will be prudent to study how to assess the difference between official land prices and actual prices. In addition to the official land prices, the public evaluation of land prices involves the benchmark land price, roadside land price, and property tax valuation, but assessing the differences among these three is also a topic for future research. Moreover, it must be investigated how land price differences are related to income differences or urban structure. These are future research topics. Occasionally, the MLIT or other related authorities publish the difference between the actual price and official land price as the rate of divergence, but the point where the transaction took place and the official target point are seldom the same; thus far, no quantitative relationship between the two prices has been found. Considering how strong the individual factors of land are, solving this problem will represent a significant contribution to the land price information system.

Acknowledgements The authors are grateful to the editor and anonymous referees for helpful suggestions and comments that led to the improvement of the paper. This research was supported by JSPS KAKENHI Grant no. 18K017061 and Nanzan University of Pache Research Subsidy I-A-2 for the 2021 academic year.

Availability of data and material The data that support the findings of this study are openly available from the Ministry of Land, Infrastructure, Transport and Tourism at https://www.land.mlit.go.jp/landPrice/ AriaServlet?MOD $=2 \& \mathrm{TYP}=0$. 


\section{Declarations}

Conflict of interest Yuta Kanno and Takayuki Shiohama declare that they have no conflict of interest.

Code availability The $\mathrm{R}$ source codes are available upon request.

\section{References}

Arundel R, Hochstenbach C (2020) Divided access and the spatial polarization of housing wealth. Urban Geogr 41(4):497-523

Bagan H, Yamagata Y (2012) Landsat analysis of urban growth: how Tokyo became the world's largest megacity during the last 40 years. Remote Sens Environ 127:210-222

Chen MC, Tsai IC, Chang CO (2007) House prices and household income: do they move apart? Evidence from Taiwan. Habitat Int 31(2):243-256

Chica-Olmo J, Cano-Guervos R, Chica-Rivas M (2019) Estimation of housing price variations using spatio-temporal data. Sustainability 11(6):1551

Cressie N (1985) Fitting variogram models by weighted least squares. J Int Assoc Math Geol 17(5):563-586

Cressie N (1993) Statistics for spatial data. Wiley, Hoboken

Cressie N, Hawkins DM (1980) Robust estimation of the variogram: I. J Int Assoc Math Geol 12(2):115-125

Cressie N, Huang HC (1999) Classes of nonseparable, spatio-temporal stationary covariance functions. J Am Stat Assoc 94(448):1330-1340

Derdouri A, Murayama Y (2020) A comparative study of land price estimation and mapping using regression kriging and machine learning algorithms across Fukushima prefecture, Japan. J Geogr Sci 30(5):794-822

Fisher J, Gatzlaff D, Geltner D, Haurin D (2003) Controlling for the impact of variable liquidity in commercial real estate price indices. Real Estate Econ 31(2):269-303

Gatzlaff DH, Haurin DR (1998) Sample selection and biases in local house value indices. J Urban Econ 43(2):199-222

Gneiting T (2002) Nonseparable, stationary covariance functions for space-time data. J Am Stat Assoc 97(458):590-600

Goodman AC (1978) Hedonic prices, price indices and housing markets. J Urban Econ 5(4):471-484

Hatta T, Ohkawara T (1993) Population, employment, and land price distributions in the Tokyo metropolitan area. J Real Estate Financ Econ 6(1):103-128

Hein C, Pelletier P (2006) Cities, autonomy, and decentralization in Japan. Taylor \& Francis, Berlin

Hill RJ (2013) Hedonic price indexes for residential housing: a survey, evaluation and taxonomy. J Econ Surv 27(5):879-914

Hochstenbach C, Arundel R (2020) Spatial housing market polarisation: national and urban dynamics of diverging house values. Trans Inst Br Geogr 45(2):464-482

Inoue R, Kigoshi N, Shimizu E (2007) Visualization of spatial distribution and temporal change of land prices for residential use in tokyo 23 wards using spatio-temporal kriging. In: Proceedings of 10th international conference on computers in urban planning and urban management, vol 63, pp 1-11

Kikuchi T (2008) Recent progress in Japanese geographical studies on sustainable rural system: focusing on recreating rurality in the urban fringe of the tokyo metropolitan area. Geogr Rev Jpn 81(5):336-348

Kubo T (2020) Divided Tokyo: housing policy, the ideology of homeownership, and the growing contrast between the city center and the suburbs. In: Divided Tokyo, Springer, pp 21-46

Kubo T, Yui Y (2020) The rise in vacant housing in post-growth Japan. Springer, Berlin

Leung CKY, Leong YCF, Wong SK (2006) Housing price dispersion: an empirical investigation. J Real Estate Financ Econ 32(3):357-385

Li Y, Monzur T (2018) The spatial structure of employment in the metropolitan region of Tokyo: a scaleview. Urban Geogr 39(2):236-262

Matheron G (1963) Principles of geostatistics. Econ Geol 58(8):1246-1266 
Mochida N (2008) Fiscal decentralization and local public finance in Japan. Routledge, England

Modai-Snir T, van Ham M (2018) Neighbourhood change and spatial polarization: the roles of increasing inequality and divergent urban development. Cities 82:108-118

Nozawa Y, Higuchi Y (2001) A study of derivation and changes of excess commuting in the Tokyo metropolitan area. Stud Reg Sci 31(1):149-161

Ohnishi T, Mizuno T, Watanabe T (2020) House price dispersion in boom-bust cycles: evidence from Tokyo. Jpn Econ Rev 71(4):511-539

Omura K (2010) Structure and problems of the Tokyo metropolitan area: the future of peripheries. disP Plan Rev 36(50):46-181

Rosen S (1974) Hedonic prices and implicit markets: product differentiation in pure competition. J Polit Econ 82(1):34-55

Saita Y, Shimizu C, Watanabe T (2016) Aging and real estate prices: evidence from Japanese and US regional data. Int J Hous Markets Anal 9(1):66-87

Sakai T, Kawamura K, Hyodo T (2016) Logistics facility distribution in Tokyo metropolitan area: experiences and policy lessons. Transp Res Procedia 12:263-277

Schabenberger O, Gotway CA (2005) Statistical methods for spatial data analysis. CRC Press, Hoboken

Sutton GD (2002) Explaining changes in house prices. BIS Q Rev 32(1):46-60

Tiwari P (2000) Housing demand in Tokyo. Int Real Estate Rev 3(1):65-92

Van Nieuwerburgh S, Weill PO (2010) Why has house price dispersion gone up? Rev Econ Stud 77(4):1567-1606

Wang R, Derdouri A, Murayama Y (2018) Spatiotemporal simulation of future land use/cover change scenarios in the Tokyo metropolitan area. Sustainability 10(6):2056

Yokohari M, Brown RD, Takeuchi K (1994) A framework for the conservation of rural ecological landscapes in the urban fringe area in Japan. Landsc Urban Plan 29(2-3):103-116

Zheng XP (2007) Economies of network, urban agglomeration, and regional development: a theoretical model and empirical evidence. Reg Stud 41(5):559-569

Zhou H, Gao H (2020) The impact of urban morphology on urban transportation mode: a case study of Tokyo. Case Stud Transp Policy 8(1):197-205

Publisher's Note Springer Nature remains neutral with regard to jurisdictional claims in published maps and institutional affiliations. 